\title{
NUEVAS APORTACIONES SOBRE EL CUADRO "LA VIRGEN DEL ROSARIO" PROCEDENTE DEL ANTIGUO CONVENTO DEL CARMEN DE SEVILLA”, ATRIBUIDO A MURILLO.
}

\author{
ALBERTO ÁLVAREZ CALERO \\ Universidad de Sevilla
}

\begin{abstract}
Resumen.
Según la bibliografía artística de los siglos XVIII/XIX, el cuadro "La Virgen del Rosario" que estuvo ubicado originariamente en el convento del Carmen de Sevilla fue realizado por Murillo. Tras exponerse el lienzo en los años 1913/14 en Londres por la National Gallery, dentro de una exposición de pintura española, la obra se alejó poco a poco del ámbito de los estudiosos del Arte. Cuando el cuadro pasó dos décadas más tarde a una colección privada americana, los historiadores del arte no supieron más de él. En los catálogos modernos de Murillo se ignora este cuadro, o se confunde con el que está en el Palacio Pitti (Florencia), que es casi idéntico. En este artículo se reseñan más bibliográficas antiguas y a su vez datos técnicos recientes que hacen razonar que el cuadro en cuestión fue hecho realmente por Murillo, y antes incluso que la versión "florentina" de la misma advocación.
\end{abstract}

\section{Palabras clave}

Murillo, Virgen del Rosario, Convento del Carmen de Sevilla, Casa Grande del Carmen de Sevilla, Palazzo Pitti.

\section{NEW CONTRIBUTIONS ON THE CANVAS "MADONNA OF THE ROSARY" FROM THE FORMER CARMEN CALZADO CONVENT OF CEVILLE, ATTRIBUTED TO MURILLO.}

\section{Abstract}

According to the artistic literature of the $18^{\text {th }} / 19^{\text {th }}$ centuries, the "Madonna of the Rosary" picture that was located originally in the Carmen convent of Seville was realized by Murillo. After be exposing the canvas in the years 1913/14 in London in support of National Gallery, in an exhibition of Spanish painting, the work moved away little by little from the scope of the experts of Art. When the picture went on two decades later to a private american collection, the Art historians did not know any more about it. In the modern catalogues of Murillo this picture is ignored, or gets confused with the one that is in the Pitti Palace (Florence), which is almost identical. In this article there is contributed more ancient bibliographic data and technical recent information that make reason that the picture in question was made really by Murillo, and even before that the "Florentine" version of the same theme.

\section{Keywords}

Murillo, Virgen del Rosario, Madonna with the Rosary, Palazzo Pitti, carmelit convent of Seville, convent Great House of the Carmen of Seville. 


\section{Introducción.}

Quien suscribe este presente artículo publicó hace pocos años una investigación referida a los dos cuadros que estuvieron en el antiguo convento del Carmen Calzado de Sevilla atribuidos, según la bibliografía más antigua, a Bartolomé Esteban Murillo: un Ecce Homo y una Virgen del Rosario ${ }^{1}$.

El primero de esos cuadros no es del todo desconocido en el presente comercio del arte, ya que estuvo expuesto hace pocos años en la Galería Coll \& Cortés (Madrid), antes de que se vendiera finalmente a un coleccionista privado. Sin embargo, la obra la Virgen del Rosario ha pasada bastante inadvertida por los estudiosos de Murillo desde el segundo tercio del siglo XX.

En este artículo se desglosará la trayectoria de aquella Virgen del Rosario, para diferenciarlo del que está en Florencia, y con el cual se le ha confundido en algunas ocasiones. Se aportarán a su vez nuevos datos técnicos de aquel lienzo, obtenidos a partir de una restauración realizada hace escasos años. Con la unión de todos esos fundamentos teórico-prácticos se pretende contribuir a despejar dudas sobre la autoría de esta pieza pictórica, así como su etapa más o menos concreta de realización.

A su vez, este artículo aspira a que de nuevo este cuadro sea integrado en los catálogos de obras del pintor Murillo, y de esta forma sea conocido por el gran público. Se debería obviar que un catálogo de obras (sea de la materia artística que sea) no debe ser una herramienta hermética, sino que más bien debe estar sujeto a posibles revisiones y ampliaciones. Por tanto, es difícil poder cerrar de una manera tajante todo el corpus de obras de un mismo autor, cuando en cualquier momento pueden aparecer más piezas de máximo valor, como de hecho así ocurre.

\section{Las Vírgenes del Rosario de Murillo y su contextualización.}

En Sevilla, la religiosidad popular adquirió un verdadero y constante protagonismo a partir de la segunda mitad del siglo XVII. Eso fue especialmente subrayado tras el dramático episodio de la Peste de 1649, en el que pereció algo más de la mitad de la población local. En el contexto de un régimen de constante devoción y religiosidad en el que vivía la Sevilla Barroca, su población experimentó un angustioso sentimiento de culpa, de pecado colectivo, por el que Dios castigaba a la ciudad. Era preciso una conversión radical de vida a través del arrepentimiento y la penitencia, en uno de los siglos más píos de la historia de la religión católica. A partir de esos momentos de desdicha en la sociedad sevillana de la segunda mitad del s. XVII, se estrechó en la religiosidad popular el vínculo entre la fe y la piedad, entre el dogma y el culto. Entre los numerosos objetos religiosos mediante los cuales las personas católicas manifiestan su piedad y devoción, sobresale especialmente el Rosario. Éste era mucho más que un signo de oración entre los piadosos fieles del siglo XVII, sino casi un sacramento que ayudaba a obtener la propia salvación eterna.

Los distintos encargos que realizó Murillo con la temática de la Virgen del Rosario surgirían con ese mismo propósito: la de vivificar el rezo del Rosario.

Aunque sea algo meramente anecdótico, no deja de ser a su vez llamativo que el propio pintor fuera miembro de una sevillana Cofradía del Rosario, la del antiguo convento de S. Pablo (actual parroquia de la Magdalena) desde 1644. Por eso mismo, Murillo estaría especialmente predispuesto a desarrollar ese tipo de temática, y más en esos años.

En ese contexto de mediados del s. XVII, Murillo hizo en esa época varios lienzos sobre un mismo modelo iconográfico, en el que aparece la Virgen sujetando al Niño Jesús, y ambos portando el Rosario ${ }^{2}$. Son destacados en especial los tres siguientes cuadros de características

\footnotetext{
1 Álvarez, 2012: 301-314.

${ }^{2}$ No queremos incluir en esta lista el cuadro de Murillo La entrega del Rosario a Santo Domingo, que es de unas características diferente, y de una década anterior a las otras. Tampoco queremos citar la Virgen del Rosario que está en la Galería Dulwich (cerca de Londres), que es de los últimos años del pintor.
} 
similares, y reconocidos plenamente por los historiadores: el que está expuesto en el Museo Goya de Castres (perteneciente al del Louvre), el del Museo del Prado, y el de Florencia (Palacio Pitti). ${ }^{3}$

Están bien investigadas las procedencias de los dos primeros. El dilema ha surgido en las últimas décadas con la Virgen del Rosario que está en el Palacio Pitti, ya que algunos historiadores han afirmado que se trata del cuadro que estuvo en el convento del Carmen.

Las características entre el cuadro de Florencia y el que se investiga en este artículo son casi idénticas, salvo la caída del Rosario, que en el caso del cuadro florentino es menos oblicua. Ese lienzo que está en la Galería Palatina de Florencia llegó a tal sitio en 1822, cuando fue comprado por el gran duque Fernando III de Lorena por 900 escudos (18.000 reales) al pintor Védele Acciaj, que lo había adquirido a su vez del negociante romano Cartoni. Esto no aclara el primer origen de este cuadro. Es quizá por esta u otras razones la confusión con el otro cuadro.

Seguidamente se detallará el proceso seguido por la Virgen del Rosario tratado en este artículo. De esta forma, se podría deducir si dicho cuadro procedente del convento del Carmen no corresponde realmente con el que está en Florencia.

\section{El cuadro de la Virgen del Rosario desde sus orígenes en el Carmen hasta la época de la Guerra de la Independencia.}

La Casa Grande del Carmen de Sevilla era uno de los conventos más extensos e importantes de su ciudad ${ }^{4}$. En el momento en el que, según la bibliografía antigua, los frailes carmelitas encargaron a Murillo la Virgen del Rosario así como un Ecce Homo, se habían terminado de construir unas décadas antes los dos claustros del convento, de estilo barrocos, sustituyendo las antiguas edificaciones góticas que precedían al actual inmueble. Un cuarto de siglo antes se le había encargado al entonces joven Velázquez dos cuadros: San Juan en Patmos y una Inmaculada Concepción. Eran años de esplendor en el convento carmelita, pero que posteriormente menguarían a partir de la segunda mitad de esa centuria, como de forma generalizada ocurriría en toda España.

La compra de aquella Virgen del Rosario se hizo para un uso más bien doméstico, ya que según las crónicas dieciochescas el lienzo estuvo colocado en la sacristía del convento 5 .

En un manuscrito titulado "Inventario de la Sacristía del Convento de Nuestra Señora del Carmen de Sevilla", aparecen registros de datos de entre los años 1584 y 1686. En él se detallan sobre todo objetos que tenían un uso litúrgico. Sin embargo, no se hace ninguna alusión al referido cuadro, aunque eso no significa que no existiera, o bien que en ese momento estuviera colocado en otro lugar del convento. Como curiosidad, sí se nombra en dicho manuscrito un altar llamado "de los Niños". No se puede saber si ese título del altar surgió porque allí estuvieran colocados tanto el referido cuadro de la Virgen del Rosario

\footnotetext{
${ }^{4}$ Tras la Desamortización de General de Mendizábal y la consiguiente exclaustración del convento en 1835 , el mismo edificio fue reformado en el último tercio del S. XIX para adaptarlo a cuartel hasta 1979. En la actualidad, el edificio alberga el Conservatorio Superior de Música y Arte Dramático de Sevilla, tras una restauración integral realizada en los últimos años del siglo que nos precede.

${ }^{5}$ Ortiz de Zúñiga, Diego, T. 5, 1677 (rev. 1796 por Antonio Ma Espinosa): 37.

${ }^{6}$ Está depositado actualmente en la Biblioteca Rector Machado y Núñez (Universidad de Sevilla, sign. A $331 / 236)$.
} 


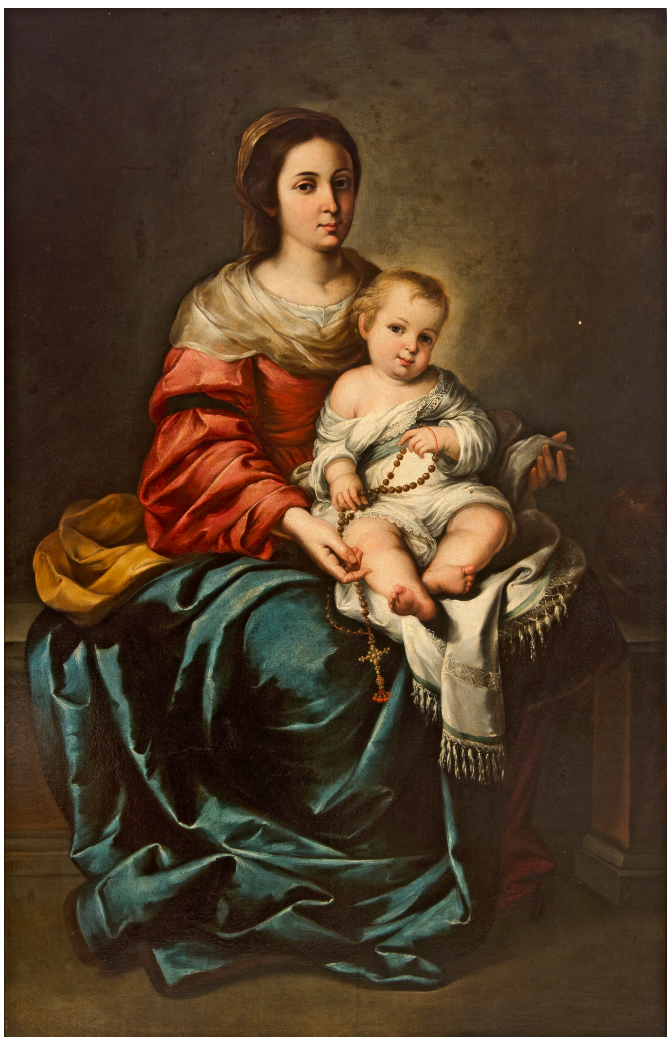

Fig. 1. Imagen de la Virgen del Rosario de Murillo que perteneció al antiguo convento del Carmen de Sevilla, y que es el motivo de estudio de este artículo.

como alguna escultura con un Niño Jesús. Al margen de los datos meramente materiales, es llamativo que aparezca registrado en ese inventario que el 8 de mayo de 1649 el sacristán fray Gerónimo González, que era músico de cierta importancia en le época ${ }^{7}$, ocupara a su vez el puesto de sub-prior durante unos meses. No sería esto especialmente llamativo si no fuera porque justo en ese momento empezó a brotar la Peste en Sevilla. Sin duda, el convento del Carmen no estuvo al margen de esa calamidad, y sin duda habría muchas bajas dentro del mismo convento.

Ya siglo y medio más tarde, a principios del siglo XIX, dicho cenobio sufrió más aún la progresiva y considerable pérdida de poder adquisitivo. De forma generalizada, la Iglesia católica española fue deshaciéndose cada vez más del enorme patrimonio artístico que poseía hasta entones, a partir de las diferentes desamortizaciones: desde la de Godoy (1798), hasta la de Madoz (1855), sin olvidar la de Mendizábal (1835-7), realmente la más acentuada de todas. Eso supuso la salida al mercado artística de innumerables obras de arte destinadas a la clientela privada. Esa situación fue especialmente llamativa en Sevilla, considerada la ciudad conventual por antonomasia. En medio de todas esas circunstancias, la invasión napoleónica apuntilló la débil situación de la Iglesia.

La Guerra de la Independencia, además de los absolutos trastornos en aspectos económicos, sociales y políticos, cambió las expectativas de los marchantes europeos, los cuales desconocían la pintura española. La situación española tan inestable ayudó mucho a que los mercaderes del arte se emprendieran con avidez hacia las obras de arte españolas, que a diferencia de las obras italianas o flamencas y holandesas estaban muy poco cotizadas.

El pintor escocés George Augustus Wallis, instalado en España desde 1807, hacía de emisario del marchante y también escocés William Buchanan, y al que le escribió la elocuente carta contándole lo siguiente: "De la escuela española no tenemos ni idea alguna en

7 Álvarez, 2015: 5-11. 


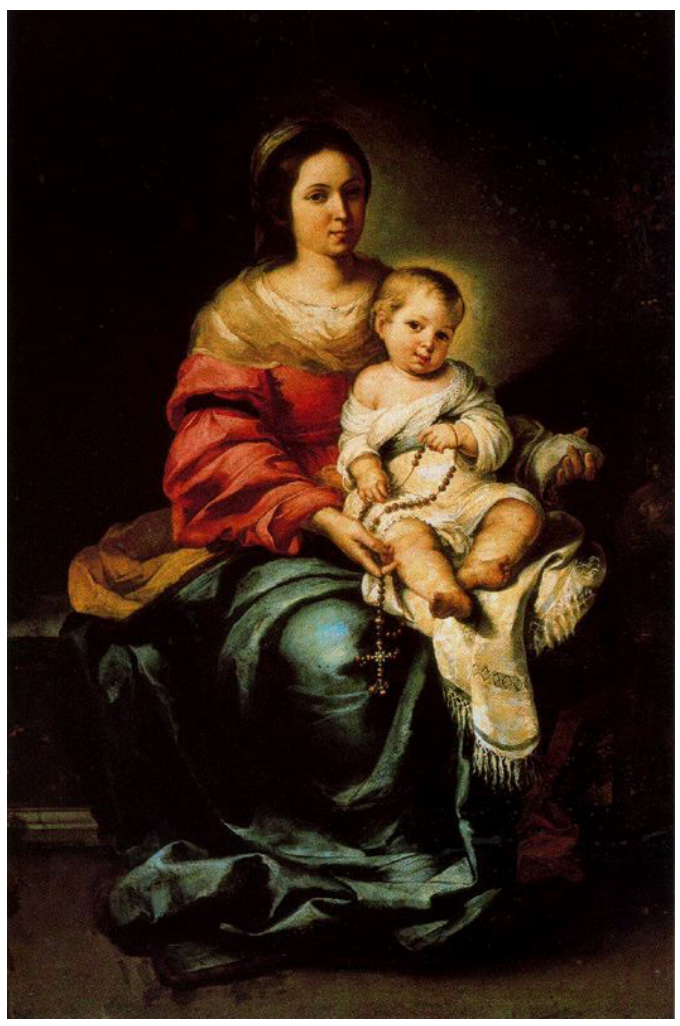

Fig. 2. Imagen de la Virgen del Rosario que está en el Palacio Pitti.

Inglaterra" ${ }^{\prime}$. Dice también en la carta que si se conociera a lo mejor de Murillo, Velázquez, El Greco, Zurbarán o Cano, "algunos estimarían la alta calidad de esta escuela". Con la llegada de las milicias napoleónicas a Sevilla el 31 de enero de 1810, ocurrió la inmediata e impúdica acción de rapiña de las obras de arte por parte de los invasores. Eso provocó que con las subastas, los soldados galos vendieran malamente piezas de calidad, en detrimento de las cotizaciones de los profesionales.

Uno de los que más se aprovechó de esa situación atípica fue el deán de la catedral de Sevilla López Cepero, conocido porque llegó a acumular un pequeño museo personal. Su actitud podría ser criticable por algunos, aunque también otros podrían decir que gracias a su avidez su colección sirvió para después erigir los fondos principales del Museo de Bellas Artes de la ciudad. Su residencia era curiosamente la casa donde llegó a habitar dos siglos antes el propio Murillo, en la plaza del Alfaro $n^{\circ} 7$. Según varios historiadores, Cepero le compró a la comunidad del referido convento carmelita los dos citados cuadros de Velázquez antes de $1809^{10}$, ya que ese año los vendió al diplomático inglés Bartholomew Frere, que fue ministro plenipotenciario en Sevilla entre noviembre de 1809 y enero de 1810, hasta que fue cesado y sustituido por Richard Wellesley, hermano del futuro duque de Wellington. Frere abandonó por tanto la capital hispalense unos instantes antes de que llegaran las tropas franceses.

Con la venida de las filas napoleónicas, los frailes de la Casa Grande del Carmen fueron expulsados, y el convento se convirtió temporalmente en cuartel de los franceses. Los caballos y la maquinaria militar circulaban con frecuencia por la que hasta entonces era la iglesia. Por eso la solería genovesa del edificio, de color azul y blanca, desapareció ${ }^{11}$, por citar

\footnotetext{
${ }^{8}$ Buchanan, 1824: 229

${ }^{9}$ Ídem.

${ }^{10}$ Justi, C.: 1999 (1º ed. 1888): 148. Bardi, P. M: 1977: 86.

${ }^{11}$ González de León: 1844: 199-200.
} 
sólo unos de los cuantiosos desperfectos que ocasionó a ese convento la llegada de las tropas de Napoleón, así como en general al patrimonio artístico sevillano.

Con todo, no se sabe a ciencia cierta cuándo ocurrió la salida del cuadro la Virgen del Rosario del convento carmelita. Se desconoce si en la venta de aquellos dos cuadros de Velázquez se incluyó también los dos de Murillo que habían en dicho convente. Hay un hecho que puede hacer pensar que la obra de Murillo que se analiza en este artículo no llegó a ser usurpado por los franceses, como sí muchos otros lienzos. Es posible que cuando los soldados galos entraron en el cenobio carmelita los cuadros de mayor valor ya no se encontrasen allí.

Dejando a un lado la particular avaricia artística del mariscal Soult y de algunos que le secundaron, en los Reales Alcázares de Sevilla se almacenaron en 1810 un total de 999 lienzos, con la idea de hacer ahí el primer museo de la ciudad ${ }^{12}$. Cuando dos años más tarde los franceses abandonaron precipitadamente Sevilla, quien encontró toda esa pila de obras fue el pintor escocés John Downie. A este hombre, casado con una sevillana, se le concedió el cargo de alcaide del Alcázar de Sevilla como agradecimiento al valor por la defensa de los españoles. José Gestoso encontró en 1896 en el mismo lugar el "Inventario de la Pintura del Palacio y Salones del Alcázar de Sevilla". De las obras de ese casi improvisado catálogo, ciento cincuenta eran de gran valor, entre los que se encontraban cuarenta y tres de la autoría de Murillo. Entre esos cuadros no se incluía la Virgen del Rosario perteneciente al convento del Carmen Calzado. Aquella misma cantidad de ciento cincuenta lienzos fueron los que los generales napoleónicos se llevaron como pudieron para Francia ${ }^{13}$.

A pesar de existir un pequeño vacío en la trayectoria de este cuadro en la etapa napoleónica, sí se sabe que años más tarde el lienzo lo poseyó el británico Julian Benjamin Williams en Sevilla. Eso hace casi corroborar que el cuadro no salió de la ciudad justo tras la Guerra con Napoleón, como se verá seguidamente.

\section{Julian Benjamin Williams: principal impulsor y exportador de cuadros de Murillo en la Sevilla de los años 1830-1833, la época de los viajeros.}

Este inglés llegó a la capital hispalense en 1818. Se casó con una española (no se sabe si sevillana), y allí vivió el resto de su vida, siendo vicecónsul inglés desde 1831 a 1856. En este último año obtuvo el cargo de cónsul ${ }^{14}$, y que lo mantendría posiblemente hasta su muerte, acontecido diez años más tarde. Su cargo le daba la facilidad de tener continuos contactos con personas adineradas, la mayoría viajeros foráneos, con las que podía hacer muchas transacciones ${ }^{15}$. Como en el consulado inglés había poco trabajo en esa época, especialmente con un puerto sevillano en decadencia, la verdadera labor que realmente había en dicha oficina era la de buscar obras de arte para después hacer la compra-venta. Por eso mismo,

12 Lo publicó Manuel Gómez Ímaz con el título Inventario de los cuadros sustraídos por el gobierno intruso en Sevilla el año de 1810 (Edición facsímil en Renacimiento, 2009). Con un sentido explícitamente hostil hacia los franceses, tras menos de cien años de la invasión, Gómez Imaz explica que la acumulación de cuadros era para enviarlos a París, cuando se ha demostrado que la intención era para exponerlos permanentemente en los Reales Alcázares.

${ }^{13}$ Cuando Napoleón perdió la guerra, gran parte de las obras artísticas fueron devueltos a sus lugares originales. Sin embargo, y a pesar de la normativa del Congreso de Viena de 1815, muchos de los mejores lienzos pasaron a coleccionismo privado. Cuando el mariscal Soult cruzó Madrid el 2 de marzo de 1813, ya de retirada, iba al frente de una caravana de furgones de cuadros andaluces, que había adquirido "gratuitamente". Cuando tras su muerte se subastó la gran cantidad de piezas apropiadas, los lienzos se dispersaron por toda Europa.

14 Cit. en The London Gazette el 13 de junio.

15 Glendinnin, 1989. 


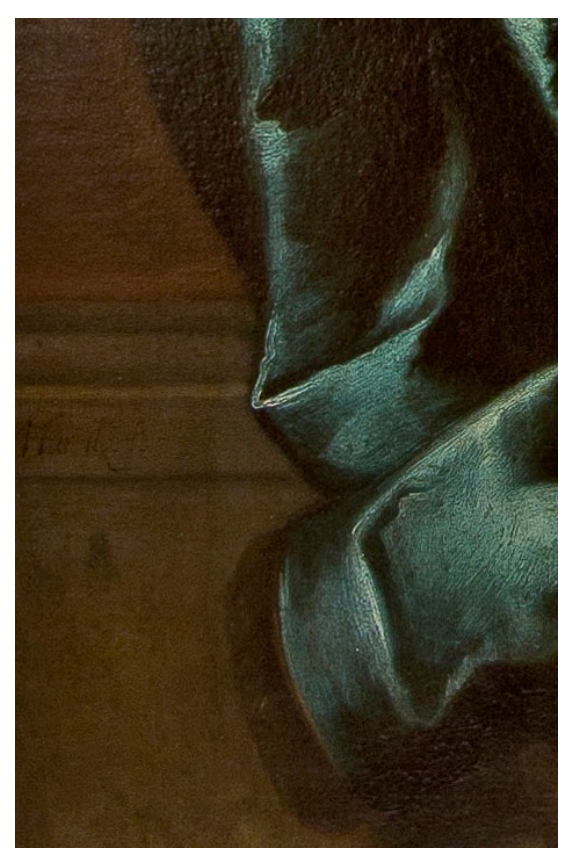

Fig. 3. Firma de Murillo localizada en la esquina inferior izquierda del cuadro que se analiza.

los cónsules ingleses en Sevilla y Cádiz compraban constantemente óleos de calidad para después remitirlos a Inglaterra. Es el mismo caso que el cónsul inglés en Cádiz entre 18221842: John Backenbury; o el propio homólogo en Sevilla: Frank Hall Standish, que llegó a Sevilla en junio de 1830, aunque permaneció allí poco tiempo. Standish, heredero de una gran fortuna, llegó a poseer doscientos veintidós cuadros de máxima calidad ${ }^{16}$. Ofreció su colección a la National Gallery de Londres a cambio de obtener un título nobiliario. Al no conseguir su codiciado propósito, como resarcimiento respecto a su gobierno inglés entregó en su testamento su rica colección al rey francés Louis Philippe. No obstante, tras la revolución de 1848 la inmensa colección de arte de este monarca galo acabó subastándose en Londres en 1853.

Pero posiblemente la mejor pinacotecas privadas en el s. XIX de arte específicamente español fue la del ya mencionado Julian Benjamin Williams. Él vivía en un palacete sevillano del siglo XVI, perteneciente al Cabildo eclesiástico ${ }^{17}$. Aunque el erudito González de León sitúa el domicilio en la antigua calle "Abades Alta" n” 26, el lugar corresponde en la actualidad al número 41 de la calle Abades. La casa es de enormes dimensiones (según los datos notariales, es de $920 \mathrm{~m} 2$ de superficie por planta), y en el presente la regenta una cadena hotelera. El edificio tiene una estilizada y elegante portada de piedra, y tras cruzar un gran zaguán, se da paso a un gran patio con galerías abiertas. Sin duda, esta residencia era el lugar idóneo para acoger a unos doscientos cuadros, según dice la Guía del forastero de Sevilla de $1832^{18}$, "todos conservados con sus cuidados e inteligencia, y se gozan muy cómodamente". La misma fuente indica que treinta y siete lienzos eran de la factura de Murillo.

Todo forastero adinerado que quisiera comprar algún cuadro importante en Sevilla solía contactar con Julian Williams. La ubicación de su casa era además privilegiada para este tipo de contactos comerciales, a pocos pasos de la Giralda.

El conocido viajero Richard Ford, que estuvo residiendo en Sevilla entre finales de 1830 y 1833, dice en su famoso Handbook: "todos los viajeros debieran consultar a don Julian Williams, nuestro cónsul, cuya información artística sólo es superada por su amabilidad,

\footnotetext{
${ }^{16}$ Lleó, 2008: 191.

17 Ídem: 187-202.

18 Guía de forasteros de la ciudad de Sevilla, 1832: 82.
} 
Fig. 4. Detalle del Rosario de este cuadro, diferente al del cuadro que está en Florencia.

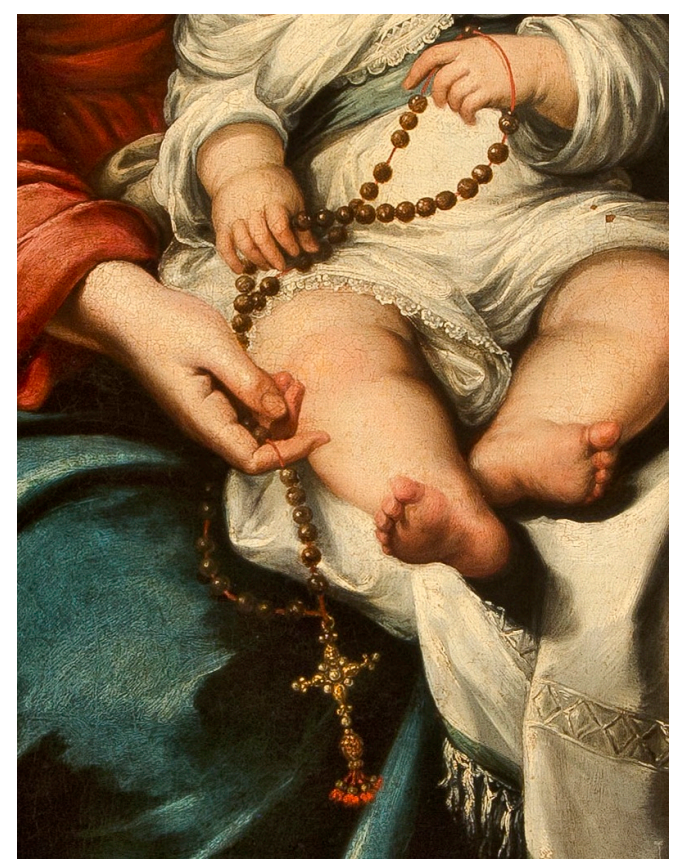

hospitalidad y cortés conducta para con sus compatriotas"19. Ford era uno de los que frecuentaba precisamente las tertulias artísticas que organizaba Julian Williams en su casa. En esas reuniones participaba también el padre de los Bécquer, además de personalidades que estaban de paso por la ciudad.

Por ejemplo, el pintor Eugène Delacroix estuvo dos semanas en Sevilla en 1832, llegando el 23 de mayo. Provenía de una misión diplomática en Tánger, acompañando al conde de Mornay. Delacroix cenó varias veces en la casa de los Williams. En una de ellas, organizó el anfitrión una fiesta flamenca, cuyas bailaoras eran sus dos hijas ${ }^{20}$. Eso demuestra cómo estaba de arraigado Julian Williams a la cultura sevillana, y cómo agasajaba en su casa sin tacañería alguna a los visitantes de cierto renombre.

En mayo del año 1833 llegó a Sevilla el paisajista escocés David Roberts en su recorrido por España, teniendo como destino final igualmente Tánger. Este pintor estuvo cinco meses en la capital hispalense, realizando numerosos acuarelas y óleos de diferentes rincones de la ciudad, y que después en 1836-7 se publicarían con éxito en Londres en litografías y grabados $^{21}$. Este pintor iba también a la casa de Julian Williams con asiduidad, al igual que en 1835 lo hacía el barón Taylor.

Éste último tenía la función en España de conseguir la mayor cantidad de obras de arte en poco tiempo a cargo y cuenta personal del rey Louis Philippe, y más tras la oportunidad comercial que ofrecía la Desamortización. Gracias a esa gestión, se inauguraría en 1838 la Galería Española en el Museo del Louvre ${ }^{22}$.

La casa de Julian Williams se convirtió por tanto en la década de los años 30 del s. XIX

${ }^{19}$ Ford, 1980 (versión española): 204.

${ }^{20}$ Julian Williams tuvo además dos hijos.

${ }^{21}$ Eso permitiría que la sociedad culta del norte de Europa tuviera conocimiento de esos lugares tan inhóspitos para ella.

22 Esta nueva sala estaba formada por cuatrocientas doce obras españolas, además de unas cincuenta de otros estilos. Unos años antes apenas había cuadros del estilo español en la misma pinacoteca. 


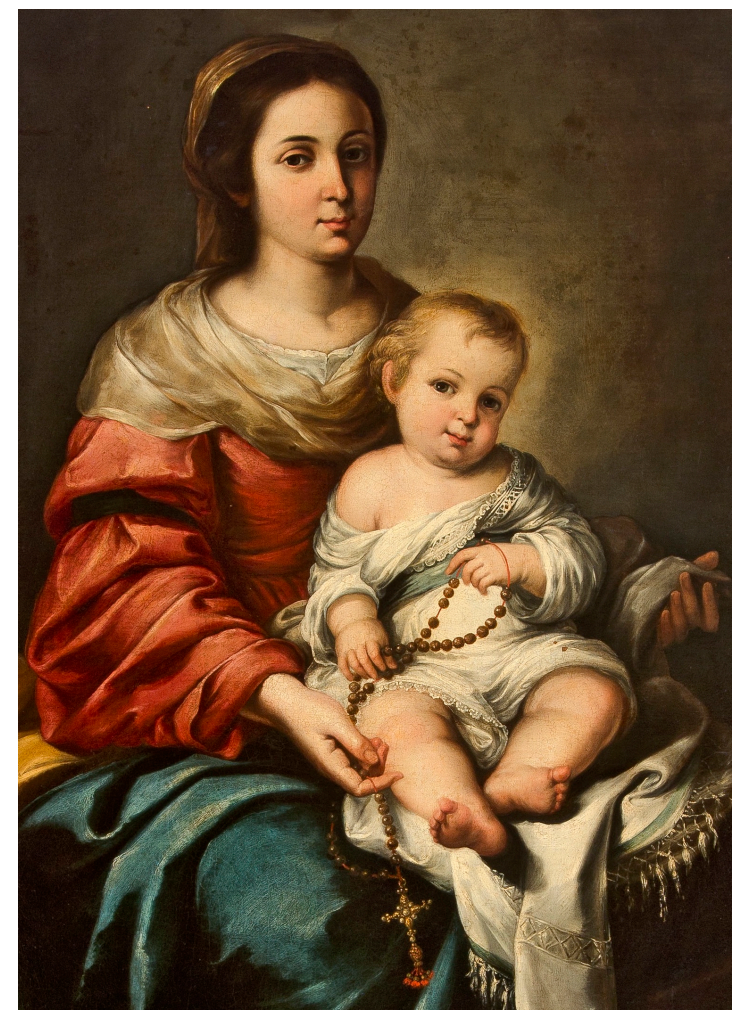

Fig. 5. Detalle más cerca de las imágenes del cuadro.

en un punto de encuentro de artistas, marchantes y diplomáticos. Más en concreto, cómo se ha comentado antes, en esos años la actividad comercial, social y cultural fue frenética en torno a Williams. En una carta mandada por Richard Ford el 11 de enero de 1832 desde Sevilla a Henry Addington, plenipotenciario británico en Madrid, le dice: "aquí estamos todos locos con los cuadros, tanto comprando como vendiendo. Cuando el mecenas Standish y este eminente conocedor, el capitán Cook, lleguen, el mercado habrá quedado limpio"23. Eso describe perfectamente el ambiente que se estaba viviendo en Sevilla con respecto a la furor por poseer y vender obras de arte. Ford adquirió de Williams un total de cinco cuadros de Murillo, según detalló el viajero en dos cartas distintas escritas al marchante de arte Dominic Calnaghi, a quien le enviaba los cuadros para su conservación ${ }^{24}$.

Williams y Ford estrecharon una cálida amistad, más allá de cualquier ambición mercantil. Por ejemplo, uno de los dibujos que el propio Ford hizo en Sevilla lo realizó en la azotea de la citada casa de William, y lo tituló "The Giralda Tower and the Cathedral of Sevilla, from the mira[dor] of the V.Consul House, Calle Abades. Feb. 1831". A su vez, Williams le regaló a él un dibujo de un Crucificado de Murillo, que pertenecía a la familia del Conde de Águila.

En el círculo de Ford y Williams también estaba el inglés Sir William Eden, que estuvo viviendo en Sevilla en el año de 1831, aunque algunos historiadores dicen que su viaje por España lo hizo entre 1832-33 ${ }^{25}$. Ford decía en una carta lo siguiente sobre este diplomático: "Sir William Eden es muy pegajoso y bizarro. No sospechaba fuese tan aficionado y coleccionista" 26 . A pesar de estas palabras de cierta tirantez, lo cierto es que después ambos británicos tuvieron una buena relación. Tanto es así que Richard Ford dedica su conocido

\footnotetext{
${ }^{23}$ Cit. en Lleó, 2008: 187.

${ }^{24}$ Idem., 196-197.

25 Glendining, 2010: 59.

${ }^{26}$ Cit. en Ford, B., 1963.
} 
Fig. 6. Detalle del Niño Jesús, que soporta el rosario

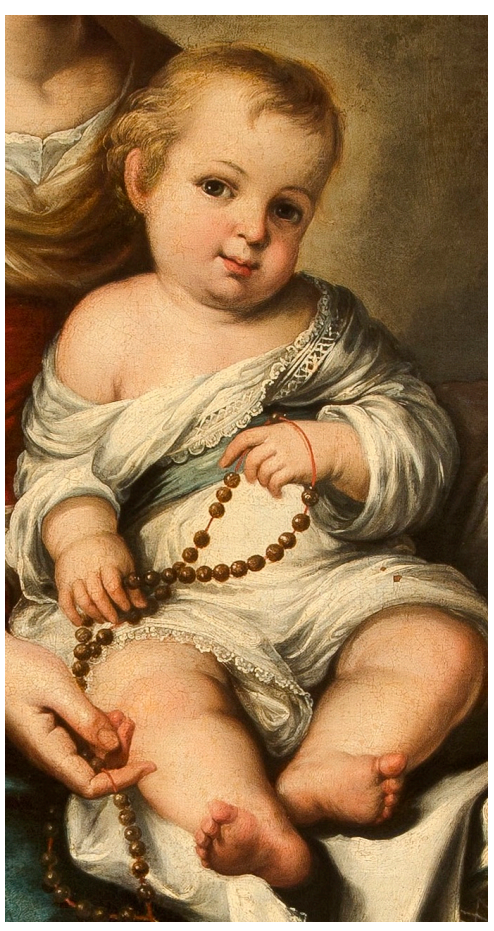

manual para viajeros al propio William Eden, como "recuerdo de los agradables años pasados en la bien querida España",27.

Según Curtis, ${ }^{28}$ Sir William Eden le compró en 1834 a Julian Williams el cuadro de Murillo la Virgen del Rosario, al que se dedica este artículo, además de otros dos lienzos del mismo autor: Visión de San Francisco en la Porciúncula, perteneciente originariamente al convento de los Capuchinos de Sevilla; y la Virgen de la Manzana ${ }^{29}$.

Julian Williams fue el primer poseedor particular que se sepa seguro del cuadro de la Virgen del Rosario procedente del convento carmelita. El inglés fue capaz de combinar su amor al arte con el oficio de marchante. Con esa premisa, él vendió gran parte de su extensa y cotizada colección entre esos años de 1831-33, en los cuales los citados personajes foráneos pasaron una mayor o menor estancia en Sevilla con la intención de comprar cuadros de gran calidad. De este modo, en muy poco tiempo Julian Williams se fue deshaciendo de su amplia colección. Como decía un contemporáneo suyo, "el poseedor enriquece todos los días su colección con buenos originales que continuamente está adquiriendo y la franquea a todo aficionado que quiere sacar fruto de ella" 30 .

Amador de los Ríos afirma en su libro Sevilla pintoresca que a Julian Williams sólo le quedaban en su poder en 1844 tres lienzos de Murillo ${ }^{31}$. El propio historiador dice lo siguiente:

Esta colección inestimable daba a la Galería del señor Williams la mayor importancia entre las posesiones de cuadros de Sevilla. ¡Lástima es que se haya deshecho de tan preciosas joyas, de que no podrá en manera alguna reponerse la capital de Andalucía!’32.

\footnotetext{
${ }^{27}$ Ford, 1844: 3.

${ }^{28}$ Curtis, 1883: 152.

${ }^{29}$ Idem.

${ }^{30}$ Herrera, 1830.

31 Amador de los Ríos, 1844: 473.

${ }^{32}$ Idem.
} 


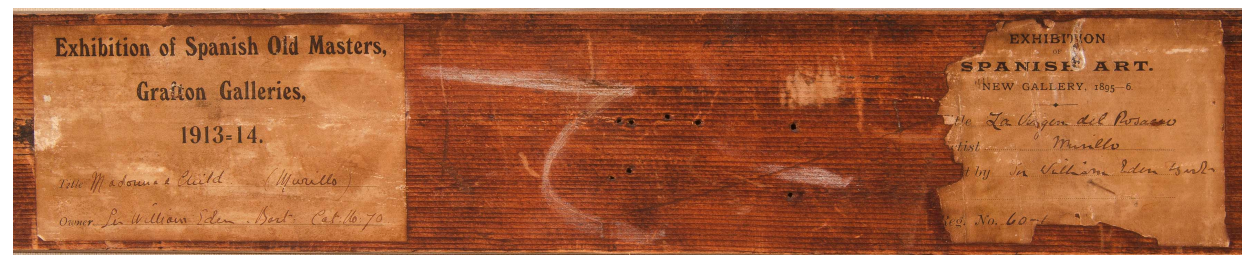

Fig. 7. En el bastidor de este cuadro se mantienen las etiquetas de las dos exposiciones importantes en las nue narticinó en I nndres

Se puede entender el hecho de que Julian Williams se desprendiera de su gran colección casi por las similares razones por las que Richard Ford hiciera lo mismo poco después con su no menos envidiable colección de lienzos adquiridos en España. En otra misiva de éste último a Henry Addington dice lo siguiente:

estoy a punto de vender mis cuadros españoles, que estaban en las casas de otros; no me causan placer y me crean problemas y gastos. El placer está en la adquisición, y no en la posesión" 33 .

Bien es cierto que a diferencia de Ford, Julian Williams tenía sus cuadros instalados en su propia casa sevillana, y no desperdigados por diferentes lugares.

La siguiente trayectoria del cuadro La Virgen del Rosario hasta la actualidad.

Sir William Eden fue por tanto el siguiente propietario de aquellos mencionados cuadros, y se lo llevó a Inglaterra. Eden sería a partir de 1844 el $6^{a}$ barón del oeste Auckland, residiendo en Windlestone House, en Durham (al norte de Inglaterra). Este aristócrata ya era $4^{a}$ barón de Maryland desde 1814. Tras su muerte, esos citados lienzos de Murillo pasaron al siguiente $7^{\circ} / 5^{\circ}$ barón de Eden, su hijo también llamado Sir William Eden (1849-1915), que llegó a dedicarse en cierta medida a la pintura.

Siendo éste último el siguiente propietario de la Virgen del Rosario y de los otros dos cuadros de Murillo heredados, ellos fueron expuestos en dos ocasiones en Londres, dentro de dos exposiciones de obras de arte española. En concreto, en la Exbibition of Spanish Art (18956) ${ }^{34}$, y en la Exhibition of Spanish old masters in support of National Gallery funds (1913) ${ }^{35}$. En la primera, el lienzo tenía en particular el no 123 del catálogo, estando colocada casi al lado del popular cuadro de "Las Lanzas" de Velázquez, que tenía el n 121; en la otra exposición, esta Virgen del Rosario de Murillo tenía el no 70.

El siguiente dueño de este cuadro fue Sir Timothy Eden (1893-1963), 8\% /6º barón de Eden, hijo del anterior propietario de aquellos cuadros. Recibió los títulos nobiliarios un año antes de ser prisionero por los alemanes en Ruhleben, a $10 \mathrm{kms}$. de Berlín, durante la I Guerra Mundial. Timothy Eden destacó por ser escritor y un pintor aficionado. A pesar de esto último, fue sin embargo quien de esta noble familia se deshizo pronto de este cuadro, poniéndolo en subasta mediante la compañía Christie en 1926. Se puede suponer que el cuadro no se llegó a vender en ese momento, pues se volvió a poner en subasta en 1932, en la Sotheby de Nueva York. Después pasó a la Newhouse Galleries, en la misma ciudad.

Fue entonces cuando lo compró el pianista y director de orquesta español José Iturbi (1895-1980) por 80.000 dólares. Esto coincidió con el momento más culminante de la carrera de Iturbi, que llevaba ya por entonces tres años afincado en California (EE.UU). Este músico amplió su trayectoria musical al ser reclamado por la famosa productora Metro Goldwyn Meyer como pianista para algunas comedias musicales.

\footnotetext{
${ }^{33}$ Ford, B., 1974: 88.

34 The New Gallery, 1895: 28-29.

35 Grafton Galleries: 1913: 76.
} 
Tres décadas más tarde de la muerte de Iturbi, sus herederos vendieron en el año 2008 su antiguo hogar, y el comentado cuadro pasó a la casa de subastas Bonhams en Los Ángeles (EE.UU.). En junio de ese mismo año, el lienzo de la Virgen del Rosario fue adquirido por otro particular. Aquella empresa de subastas de arte no se preocupó por comprobar minuciosamente la autenticidad o no de la obra, diciendo simplemente que era un cuadro del círculo de Murillo.

\section{Defensores y detractores de la autoría de la Virgen del Rosario perteneciente originariamente a los carmelitas.}

Desde el siglo XVIII hay fuentes que citan la Virgen del Rosario de Murillo que perteneció al convento del Carmen de Sevilla, y que no corresponde con el lienzo que está en Florencia. Por ejemplo, el historiador y académico Antonio Ponz llega a decir en su libro Viages de España (1772) que se trata de "una de las pinturas más bellas de Murillo" ${ }^{36}$. Lo mismo opina Ortiz, como anteriormente se comentó. Ceán Bermúdez, en su Diccionario Histórica (1800) la describe como "una excelente Virgen de cuerpo entero sentado con el Niño" ${ }^{37}$. En los Annales eclesiásticos y seculares de Ortiz de Zúñiga (en la revisión y ampliación hecha por Espinosa en 1795) se dice lo siguiente: en la "hermosa y adornada" sacristía de ese antiguo cenobio carmelita, (...) en el trastero principal, en un altar se halla una imagen de la Virgen sentada con su Niño, cosa muy buena, de Murillo"38.

Los estudiosos de mediados del siglo XIX, tanto González de León y Francisco Tubino como los extranjeros Edward Head y William Stiring, no hacen sino transcribir casi literalmente lo ya expuesto por los anteriores historiadores, recalcando la belleza del cuadro ${ }^{39}$. Tubino incluso afirma que el cuadro lo compró W. Eden al citado Julian William, a la vez que los ya citados de la "Virgen de la Manzana" y "La Porciúncula"40.

Otras reseñas similares un poco más posteriores son las que aparecen en la revista "The Atheneum" (1877) ${ }^{41}$ y en el libro de Moses Foster Sweetser Artistbiographies (1880) ${ }^{42}$.

Por otro lado, para diferenciar la Virgen del Rosario florentina con la que estuvo en el sevillano convento carmelita, es muy significativa la aportación de la antigua antología de ilustraciones publicado por el historiador del arte August L. Meyer en $1913^{43}$. Sin embargo, en la edición de este mismo libro de 1923 Meyer se retrotrae de que la autoría de este cuadro es de Murillo. Incluso en un artículo suyo escrito en 1934 piensa que el cuadro expuesto en Florencia es el que procede del convento del Carmen, y no el que durante décadas perteneció a la familia de los Eden. Dice por tanto todo lo contrario de lo dijo en la primera edición de su libro. Critica en su artículo de 1934 la opinión opuesta de autores como Ponz y Bermúdez. Dice Meyer lo siguiente sobre la confusión entre los dos cuadros similares:

Si buscamos explicación hay dos posibilidades: La primera, que Ponz no conoció el ejemplar de Florencia y que el estado algo sucio no hizo resaltar las deficiencias especiales de la pintura. La segunda, que el cuadro que Ponz y Bermúdez vieron no era la «Madonna Eden» sino el ejemplar hoy en Florencia ${ }^{44}$.

36 Ponz, 1772: 103.

37 Bermúdez, 1800: 59 (vol. II).

38 Ortiz de Zúñiga, T. 5, 1677 (rev. 1796 por Antonio Ma Espinosa): 37.

${ }^{39}$ González de León, 1844: 199. Tubino, 1864: 205. Head, 1848: 186. Stirling, 1848: 1420.

40 Tubino, 1864: 205.

41 "The Atheneum", 1877: 216.

42 Swwtser, 1880: 131.

43 Mayer, 1913: 27. La imagen del cuadro que se investiga en este trabajo aparece en dicho libro con un defectuoso enfoque del flash de la cámara, lo que dificulta la apreciación de la obra.

44 Mayer, 1934: 17-18. 


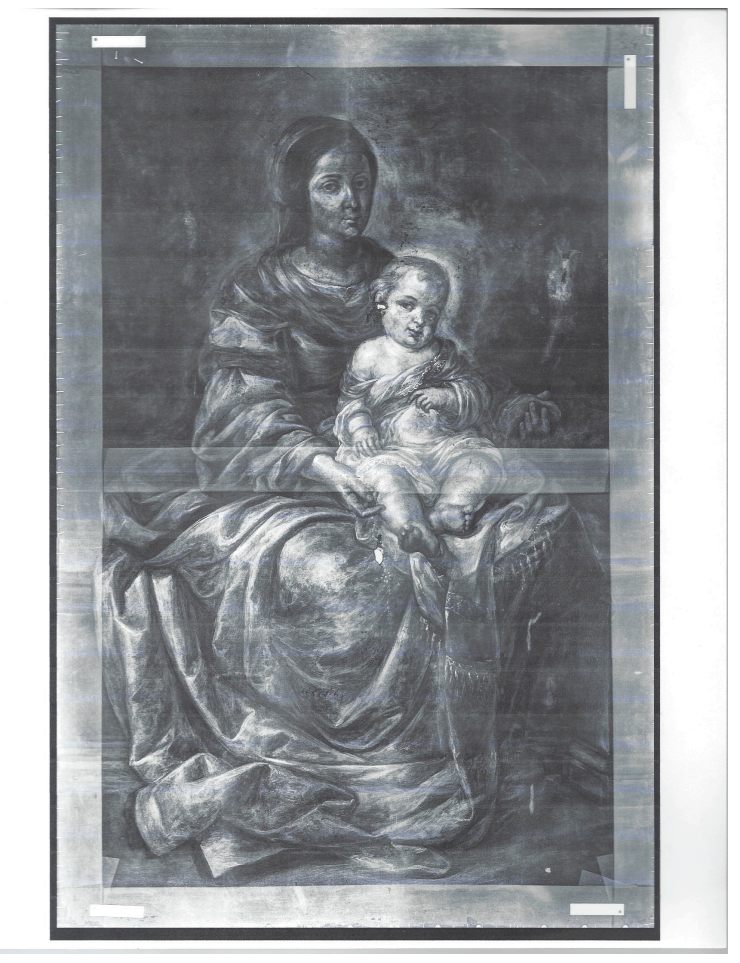

Fig. 8. Esta es una de las radiografías del cuadro realizadas por los restauradores Icono I\&R, en la que se aprecia los desperfectos que tenía el lienzo; en particular, en la oreja derecha del Niño, y en un punto concreto de la tela de la Virgen.

Añade en este artículo Meyer otra razón al hablar de las dimensiones de los dos cuadros, al comentar lo siguiente: "El ejemplar de Florencia tiene el tamaño regular de la mayoría de tales «Vírgenes» de Murillo, mientras la «Madonna Eden» es algo mayor" ${ }^{45}$.

Ya en tiempos más modernos, el insigne Diego Angulo llega a mezclar los dos cuadros, afirmando en su famoso catálogo de Murillo lo mismo que Meyer, que el que está en Florencia es el que provenía del convento del Carmen ${ }^{46}$. Muchas de las descripciones de posteriores historiadores no hacen sino repetir esa misma idea de Angulo.

\section{Aportaciones técnicas tras la restauración del referido cuadro.}

En el estudio madrileño de restauración Icono I\&R se hizo en el año 2014 una restauración completa del cuadro que se investiga en este artículo. Posteriormente, los restauradores hicieron un informe técnico y analítico sobre este alusivo cuadro. Dicho trabajo aporta datos novedosos e interesantes sobre la época en el que fue realizado este lienzo. Pero sobre todo, sus resultados permiten aclarar mucho más la hipótesis de que Murillo es el autor de la obra, como seguidamente se verá con bastante precisión.

Según el estudio de la superficie mediante reflectografías de infrarrojos, existen algunos puntos donde se observan trazos de un fino dibujo preliminar. En concreto, los restauradores Rafael Romero y Adelina Illán lo perciben "en la línea de la boca, en el párpado superior del ojo derecho y en el contorno de la mejilla izquierda" ${ }^{47}$. Añaden los mismos restauradores que este tipo de dibujo se encuentra en varias obras del periodo temprano de Murillo. Es el caso del San Agustín con la Virgen y el Niño, en el Museo de Bellas Artes de Sevilla; en el boceto para el San Antonio de Padua pintado para la Catedral de Sevilla, y en el boceto para La Escalera de Jacob, ambos en colecciones particulares.

\footnotetext{
45 Idem.

46 Angulo, 1981 [vol. 3]:148.

47 Romero/Illán, en prensa: 21-24
} 


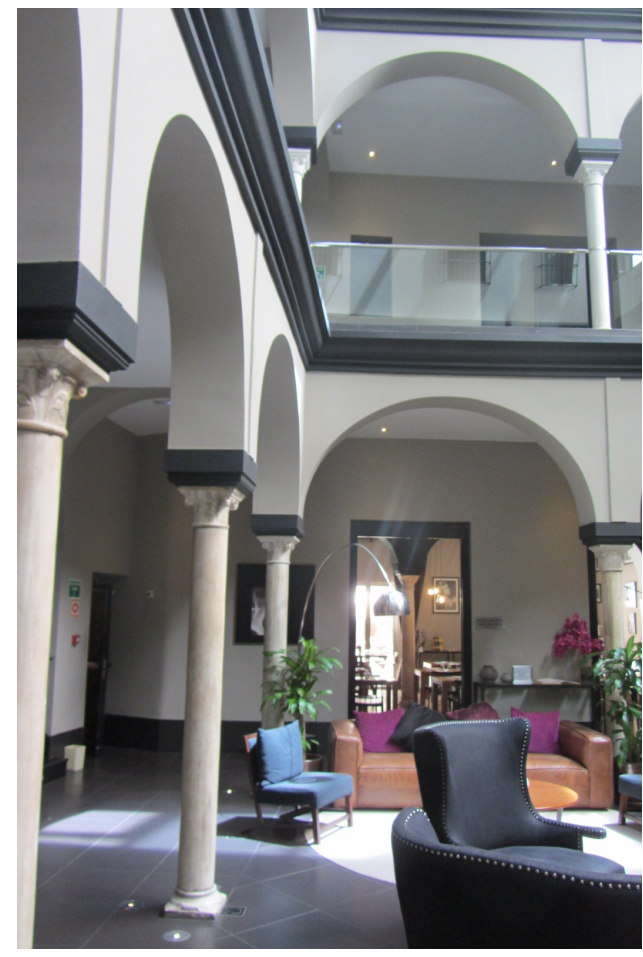

Fig. 9: Casa donde residió Julian Benjamin Williams en Sevilla (calle Abades, en el actual $\mathrm{n}^{\mathrm{o}}$ 41). En el inmueble, muy remodelada en el presente, se llegaron a albergar casi cuarenta cuadros de Murillo, entre los que se incluía la investigada Virgen del Rosario.

Los conservadores manifiestan que las pequeñas muestras tomadas de la obra revelan una preparación típica de la Sevilla del s. XVII, de color ocre-pardo. Francisco Pacheco llamaba a esa preparación "tierra de Sevilla" ${ }^{48}$. También detectan los conservadores de la obra pigmentos relacionados con la etapa juvenil de Murillo, como el amarillo de plomo y estaño (llamado en la época genulí). Eso aparece en la tela amarilla de la Virgen, colocada a la izquierda del espectador, sobre el banco.

La flamante restauración del cuadro hace recobrar el color intenso que originariamente tenía. Curiosamente, para el manto de la Virgen el autor optó por un color azurita de gran calidad, al contrario que en otras obras suyas en las que se combina un pigmento azul pobre con otro mucho mejor, como el mencionado Azurita. Sin duda, la importancia del encargo hizo que el pintor optara por ese pigmento azul exclusivo para el manto. Salvo eso, la paleta empleada para esta obra es la habitualmente usada por Murillo, "particularmente en su periodo temprano, en el que no incluye todavía pigmentos extraordinariamente caros para la época como el lapislázuli’" ${ }^{\prime 4}$, en palabras de los restauradores de Icono I\&R.

El estudio radiográfico manifiesta un limitado número de arrepentimientos en el trazado de la obra. En ese sentido, el artista modificó, según la radiografía, "el contorno del hombro y brazo izquierdos del Niño, así como la cabeza en esta zona, reduciendo la robustez de la figura" ${ }^{50}$. La cruz del rosario parece estar originariamente más para abajo de cómo se ve, habiéndose reducido su tamaño. También desvela la radiografía que un cambio en un gran pliegue del manto de la Virgen, a la altura del suelo y a la derecha del espectador. Originariamente se extendía más hacia la derecha, y posteriormente sube hacia arriba. Por último, los restauradores indican que la longitud de los flecos del paño del Niño fue modificada por el pintor sobre el primer trazo realizado.

\footnotetext{
${ }^{48}$ Ídem.

${ }^{49}$ Ídem.
} 
Fig. 10. Por menor del rico artesonado que estaba colocado en una de las salas de la residencia sevillana de Julian Williams, y que en la actualidad corona el patio, tras su remodelación para ser un hotel.

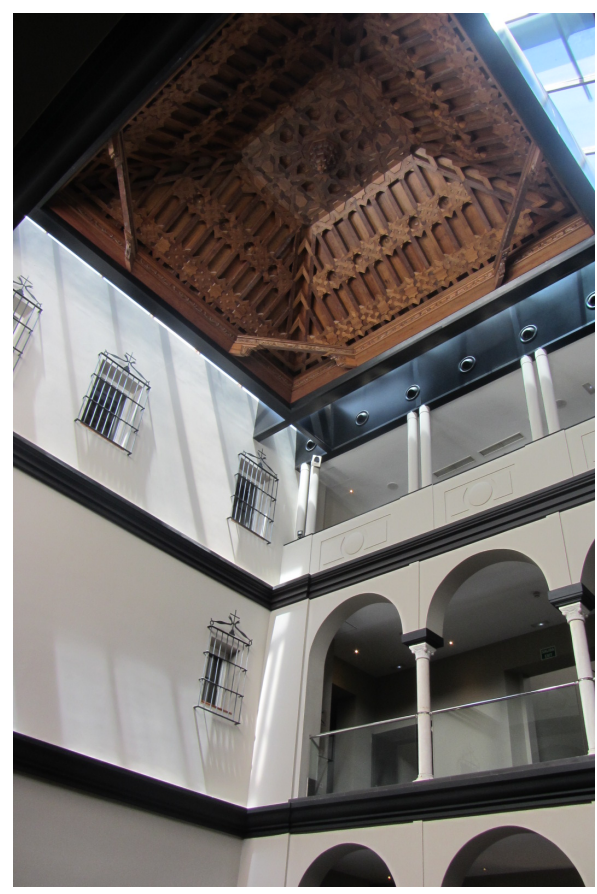

El estado de conservación de este cuadro al llegar a las manos de los citados restauradores era bueno. Sólo señalan éstos en su estudio posterior un pequeño agujero en la oreja derecha del Niño y un roto o desgarro en el manto azul bajo la pierna derecha de la Virgen.

\section{Discusión.}

La menor calidad del trazado en la oreja del Niño Jesús de este cuadro antes de la última restauración se explica con el agujero que mencionan los restauradores que había en el lienzo, y que se evidencian en las radiografías.

En la restauración realizada en torno al año 1934, antes de que Newhouse Galleries lo vendiera a Iturbi, parece que se intentó disimular de una manera torpe ese defecto. En esa intervención se hicieron nuevos repintes y se revisó el bastidor. Eso hizo que, más que florecer las virtudes del cuadro, acabara haciendo pensar ante algunos que el lienzo es una buena copia, como es el caso de Meyer.

Sin embargo, la última rehabilitación del cuadro permite ahora disimular el anterior defecto de la oreja del Niño, y por tanto aleja al espectador crítico aquella idea de que el cuadro fuera una copia.

Las razones que argumenta Meyer al final para desmontar la autoría del cuadro no son justificables. Especialmente al referirse al mayor tamaño del cuadro que se estudio en estas páginas. Las dimensiones están dentro de los modelos estándar de otros cuadros similares de Murillo. Las medidas exactas del cuadro de Florencia son de 165 x 109 cms., y las del cuadro que se estudia son casi iguales: 167,2 x 111,5 cms. Las dimensiones de la Virgen del Rosario que está en el Museo del Prado son de 166 x $112 \mathrm{cms}$., y las de Castres son incluyo mayores en total: $166 \mathrm{~cm} \times 125 \mathrm{cms}$.

Hay una pista más sobre la autoría del cuadro que se analiza, que aunque no es la más concluyente, contribuye a despejar más dudas: y es la propia firma del autor en el lienzo. Si bien es cierto que una firma, al igual que todo el cuadro, podría ser falsificada, lo cierto es que en una esquina del mismo aparece la rúbrica "Murillo F", es decir Murillo fecit, o lo que es lo mismo: "Lo hizo Murillo". La firma escrita de esa forma no sólo informa de la más que posible autoría del autor, sino que aporta la idea de que el mismo pintor estuviera especialmente orgulloso del cuadro. No se trataría por tanto de un mero trabajo de taller, sino que el pintor estaría muy implicado en la realización de dicho lienzo. 


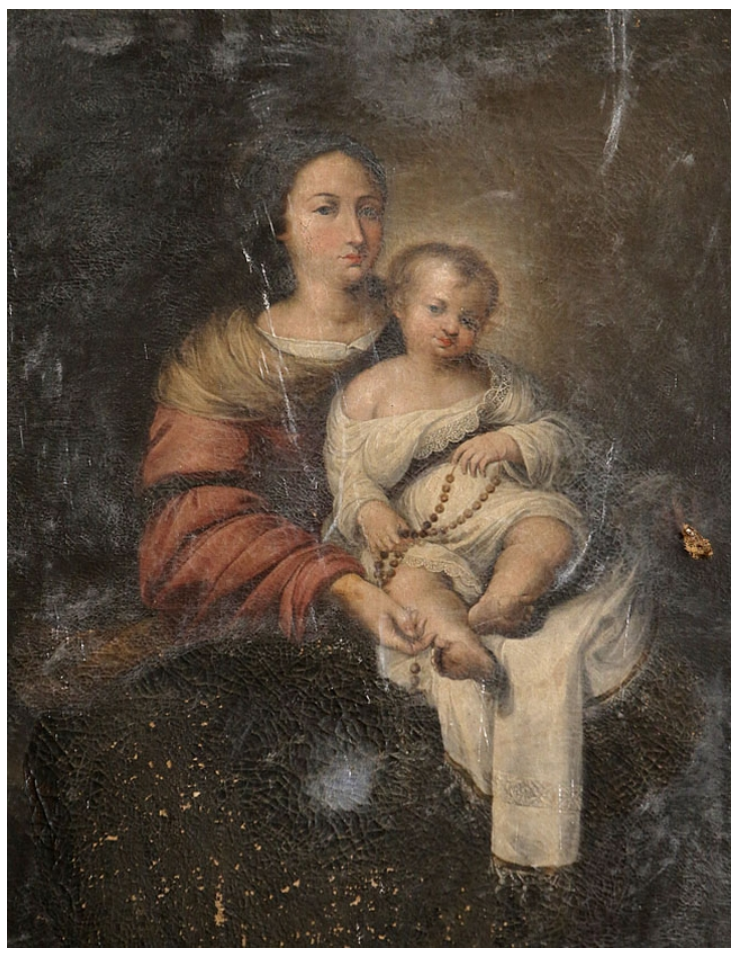

Fig. 11. Una más que posible copia de la Virgen del Rosario de Murillo, que se encuentra en Toledo.

Pero las razones que realmente concluyen que este cuadro es del universal pintor sevillano son las siguientes. La bibliografía antigua demuestra que este cuadro que se analiza es el que estuvo en su momento en el antiguo convento del Carmen de Sevilla, y no el que está en Florencia. Es difícil pensar que durante más de dos siglos los historiadores se hayan confundido, cuando ya se ha visto que en libros antiguos se diferencia un lienzo del otro. Eso derrumba los argumentos que puedan decir que el discutido cuadro es un falso Murillo. Eso sólo se podría sospechar si la obra que está en Florencia fuera realmente la que estuviera en el cenobio carmelita, algo que no es así, tal como lo demuestran diversas evidencias.

A su vez, es difícil imaginar que de los dos cuadros que según los más antiguos estudiosos de arte eran de Murillo y estuvieron colocados en los muros de ese antiguo convento carmelita, uno sea en verdad una copia. Ya se sabe que en dicho cenobio había un "Ecce Homo" realmente de Murillo, por lo que no tendría mucho sentido que la propia comunidad carmelita, una institución importante en esos momentos, adquiriese después una copia de un cuadro de Murillo, en vez de otro original del mismo pintor. Hay que recordar también que dichos frailes habían comprado previamente dos cuadros originales de Velázquez.

Tampoco tendría mucha lógica que Julian Williams, uno de los que más manejó el arte barroco español en los años 30 del siglo XIX, y teniendo durante esos años una de las mejores galerías de Sevilla, no se hubiera dado cuenta de que el cuadro que se discute en estas páginas fuera una copia. Tampoco se entendería que, de los tres lienzos de Murillo que Williams vendió a su amigo Eden, uno no fuera original..

Los datos aportados por los restauradores Icono I\&R revelan mucho sobre la autoría de esta comentada Virgen del Rosario. Los tipos de pigmentos hacen situar el cuadro al final de la etapa juvenil de Murillo, en torno a 1645-1650. La ejecución de la obra es muy directa, mostrando una maestría notable. Es también "precisa, segura y concienzudamente estudiada" 51 por el pintor. Con esos argumentos, muy difícilmente se podría pensar que se tratase de una copia.

Además, los leves arrepentimientos en el trazado del cuadro hacen deducir que este comentado cuadro sería muy posiblemente el primero de la serie. Es decir, es probable que

51 Ídem. 
el lienzo que está en Florencia sería hecho inmediatamente posterior a este que estuvo en el convento del Carmen.

\section{Conclusiones.}

Con esta investigación se demuestra mediante fundamentos bibliográficos y técnico que el cuadro del que se ha hablado durante todas estas páginas fue realizado por Murillo. Aunque por las diversas razones ya argumentadas el lienzo ha sido olvidado por los estudiosos en tiempos modernos, eso no es óbice para que se pueda restituir su reconocimiento, el que siglos atrás tenía.

La ejecución pictórica revela en las radiografías realizadas por los últimos restauradores unas interesantes y llamativas conclusiones. Tal como ya se ha comentado anteriormente, las leves correcciones en el diseño del cuadro hacen improbable que éste se trate de una versión o copia posterior. Raramente pueden encontrarse este tipo de pentimenti en copias o segundas o terceras versiones. De hecho, esas correcciones o arrepentimientos hacen plantear que la obra pudiera ser una primera versión, y no una repetición de un original ya realizado.

Ojalá este cuadro pueda volver a ser valorado tal como le ha correspondido durante buena parte de su trayectoria, salvo la de las últimas décadas. Sería muy positivo que las instituciones andaluzas y estatales que correspondan al menos se interesasen por enjuiciar y debatir detenidamente este cuadro in situ, a partir de esta nueva perspectiva ofrecida a la comunidad científica mediante estas páginas.

\section{Apéndice.}

Como mero apéndice, queremos incluir un cuadro que por su composición y el trazado imita literalmente la Virgen del Rosario que se ha analizado en estas páginas (y por ende al del Palacio Pitti). Aquel lienzo se ha encontrado hace poco tiempo en los muros del coro del convento de San Clemente de Toledo, y no se sabe cómo llegó allí. Lo cierto es que, aunque Juan Nicolau afirma que es de Murillo ${ }^{52}$, se puede apreciar que éste cuadro "toledano" es de una calidad de ejecución muy inferior al que procedía de los carmelitas sevillanos o al que está en Florencia. Se puede observar a primera vista una gran diferencia entre una más que posible copia en el caso del cuadro que está en Toledo, con respecto a los otros dos referidos, el de Florencia y el estudiado en este artículo.

52 Nicolau, 2016. 
Bibliografía específica.

Álvarez Calero, A.: "Dos cuadros casi desconocidos de Murillos: los que se hallaban en el Antiguo Convento Casa Grande del Carmen de Sevilla". Revista Laboratorio del Arte, 24. (2012)

Álvarez Calero, A.: Fr. Gerónimo González de Mendoza (fl. 1633-1662). Valencia. Editorial Piles. (2015)

Amador de los Ríos, J.: Sevilla pintoresca. Sevilla. (1844)

Angulo Íñiguez, D.: Murillo. Su vida, su arte, su obra. Madrid, vol. III.: Espasa-Calpe. (1981)

Bardi, Pietro M.: La obra pictórica completa de Velázquez: Barcelona. Noguer, 1982.

Bermúdez, C.: Diccionario histórico, Vol. II: Madrid. (1800)

Buchanan, W.: Memoirs of Paintings, Tomo II. Londres. (1824)

Curtis, C.: Velázquez and Murillo: New York-London. (1883)

Ford, B.: Richard Ford en Sevilla. Madrid. Instituto Diego Velázquez. (1963)

Ford, B.: Richard Ford in Seville. Londres. Catálogo de una exposición. Wildenstein. (1974)

Ford, R.: Handbook for Travellers in Spain and Readers at Home. Londres. (1844)

Ford, R.: Manual para viajeros por Andalucía y lectores en casa. Madrid. Editorial Turner. (1980)

Glendining, Nigel \& Macartney, H.: Spanish Art in Britain and Ireland, 1750-1920: Studies in Reception. Woodbridge. Tamesis. (2010)

Gómez Ímaz, M.: Inventario de los cuadros sustraídos por el gobierno intruso en Sevilla el año de 1810, (1ª edición, 1896). Sevilla: Edición facsímil en Renacimiento. (2009)

González de León, F.: Noticias artísticas. Sevilla. (1844)

Grafton Galleries: Illustrated catalogue of the Exbibition of Spanish Old Master in support of National Gallery Funds and the Benefit of the Sociedad de Amigos del Arte Español, Oct 1913 to Jam 1914. Londres. (1913)

Herrera Dávila, J.: Guia de forasteros de la ciudad de Sevilla. Sevilla. (1832)

Head, Sir E.: Handbook of the history of the spanish and French schools of painting. Londres. (1848)

Justi, C.: Velázquezy su siglo (1ª edición, 1888). Madrid: Editorial Istmo. (1999)

Lection, J[¿?]: Revista The Atheneum. Londres. (1877)

Lipinski, L.: Del Greco a Goya. Obras maestras del Museo del Prado. Ciudad de San Juan (Puerto Rico). Programa de exposición en el Museo de Arte de Ponce. (2012) En https://www.museodelprado.es/coleccion/obra-de-arte/la-virgen-delrosario/eb5f85ec-f95d-4709-ab09-693206bfb3f5 [20-05-2016].

Lleó Canal, V.: "Julián Benjamín Williams y el comercio de arte en la Sevilla del XIX”. Sevilla. Colección Minervae Baetica, Vol. XXXV. (2008)

Mayer, August L.: Murillo. Des Meisters Gemälde in 287 Abbildungen, Stuttgart - Berlín. [versión inglesa en: http://www.archive.org/stream/workofmurillorep00muriuoft\#page/24/mode/2up]. (1913)

Mayer, August L.: "Anotaciones a obras murillescas" en Boletin de la Sociedad Española de Excursiones, Tomo XLII. Madrid, (1934), pp. 17-18,

Nicolau, Juan (2016): "Murillo y el convento de San Clemente", en La tribuna de Toledo, 31 de enero de 2016. En http://www.latribunadetoledo.es/noticia/ZBACB2F85-BF5A-B0221FF5D63B58B9A303/20160131/murillo/convento/san/clemente [20-05-2016].

Ortiz de Zúñiga, D. (1671-rev. 1796 por Antonio Ma Espinosa): Annales eclesiásticos y seculares de la muy noble y muy leal ciudad de Sevilla, Tomo V. Madrid.

Ponz, Antonio: Viages de España. Madrid. (1772). 
Prothero, R.: The letters of Richard Ford, 1797-1858). Londres. (1905)

Romero, C.: El Rosario en Sevilla: devoción, rosarios públicos y hermandades (siglos XV-XXI). Sevilla: Fiestas Mayores, Ayuntamiento de Sevilla. (2004)

Romero, R./Illán, A. (en prensa): Estudio técnico y analítico de la obra Virgen del Rosario, pintada por Bartolomé E. Murillo (1617-1682).

Stirling-Maxwell, W. : Annals of theartist of Spain. Londres. (1848)

Sweetser, Moses F.: Artistbiographies. Boston.( 1880)

The New Gallery: Exbibition of Spanish Art. Londres. (1895)

Tubino, F. M., Murillo, su época, su vida, sus cuadros. Sevilla. (1864)

NOTA: Las imágenes del cuadro que se analiza en este artículo son realizadas y cedidas por los restauradores Icono I\&R. Las otras fotos son de dominio público o del autor del artículo. 